\title{
The Hector Mine, California, Earthquake of 16 October 1999: Introduction to the Special Issue
}

\author{
by Michael J. Rymer, Victoria E. Langenheim, and Egill Hauksson
}

The Hector Mine, California, earthquake $\left(M_{\mathrm{w}} 7.1\right)$ struck the Mojave Desert at 09:46 UTC, 16 October 1999. The earthquake occurred approximately $55 \mathrm{~km}$ northwest of the town of Twentynine Palms, California, and about 200 $\mathrm{km}$ east-northeast of Los Angeles (Fig. 1). The shock was widely felt throughout southern California, southern $\mathrm{Ne}$ vada, western Arizona, and northernmost Baja California, Mexico. The Hector Mine earthquake, like the $M_{\mathrm{w}} 7.3$ Landers earthquake seven years earlier, was associated with fault rupture in the eastern California shear zone (ECSZ) (Fig. 1), which is an approximately $80-\mathrm{km}$-wide zone of deformation that accommodates about $24 \%$ of the relative Pacific-North American plate motion (Sauber et al., 1986, 1994; Dokka and Travis, 1990; Savage et al., 1990, 2001; Gan et al., 2000; Miller et al., 2001). A block diagram highlighting some of the basic aspects of the Hector Mine earthquake is presented in Figure 2. A preliminary summary of the Hector Mine earthquake, its effects, and the response of the geoscience community is presented by Scientists from the U.S. Geological Survey; Southern California Earthquake Center, and California Division of Mines and Geology (USGS, SCEC, and CDMG, 2000).

This special issue of the Bulletin contains 35 seismologic, geologic, geophysical, and engineering studies related to the 1999 Hector Mine earthquake, its effects, and the regional geologic and tectonic setting. These articles not only build and expand upon the preliminary results of USGS, SCEC, and CDMG (2000), but they also describe and analyze crustal deformation before, during, and after the earthquake as determined by global positioning system (GPS) and interferometric synthetic aperture radar (InSAR) data. These articles also more fully describe the geologic setting and the regional effects of the earthquake. Figure 3 shows the geographic distribution of studies presented in this issue. Because of its proximity to the 1992 Landers event (epicenters about $45 \mathrm{~km}$ apart, ruptures as close as $20 \mathrm{~km}$ ), the Hector Mine earthquake offers a rare opportunity to study the interactions of two large earthquakes with these data sets.

New advances in instrumentation and event processing provided hypocentral and magnitude determinations for thousands of aftershocks in near real time. These advances led to assessment of ground shaking within minutes of the mainshock and to assessment of aftershock hazards within days of the mainshock. New techniques to measure crustal deformation, such as continuously recording GPS networks and raster-laser imaging, were used to study this earthquake.
The earthquake allowed in-depth analysis of the limitations and advantages of the InSAR method.

Like the Landers earthquake, the Hector Mine earthquake ruptured multiple faults, some of which had not been previously mapped. The Hector Mine earthquake produced predominantly right-lateral slip (Fig. 2), consistent with its location within the ECSZ. Also like Landers, the Hector Mine earthquake triggered seismicity at distances greater than the rupture length. However, unlike Landers, which triggered seismicity primarily to the north in the direction of its rupture, the Hector Mine earthquake triggered seismicity south of the rupture, in the Salton Trough region (Figs. 1 and 3 ).

We start this special issue with two articles that individually discuss the Hector Mine earthquake and associated surface faulting. Hauksson et al. describe foreshocks, the mainshock, and aftershocks of the Hector Mine earthquake. They demonstrate that temporal clusters of earthquakes in 1992 and 1996 occurred a few kilometers away from the eventual Hector Mine mainshock and migrated southeastward, toward the future epicenter. A cluster of foreshocks likewise preceded the Hector Mine earthquake, but within the immediate hypocentral volume. The Hector Mine mainshock ruptured to the north, northwest, and south as shear deformation characterized by conjugate strike-slip faulting. Treiman et al. show that the Hector Mine earthquake was associated with $48 \mathrm{~km}$ of dextral surface rupture. Complex northward rupture began on two branches of the Lavic Lake fault; rupture also propagated southward onto the Bullion fault. Lesser amounts of rupture occurred across two right steps to the south. Maximum dextral displacement was $5.5 \pm 0.5 \mathrm{~m}$; displacement averaged about $2.5 \mathrm{~m}$ along the main rupture zone. They conclude that most of the faults that ruptured in 1999 had prior late Quaternary displacement, and only limited sections of the rupture showed evidence of prior Holocene surface slip.

Ji et al. (I) use a new procedure to model rupture complexity by using static and seismic data that allows for multiple fault segments, variable local slip, rake angle, rise time, and rupture velocity. This approach combines a wavelet transform approach with a nonlinear algorithm. The resulting model, presented by Ji et al. (II), leads to a seismic moment estimate of $6.28 \times 10^{19} \mathrm{~N} \mathrm{~m}$, distributed along three rupture segments. These segments, from north to south, account for $37 \%, 41 \%$, and $22 \%$ of the total seismic moment, respectively. They calculate a rise time that appears roughly 


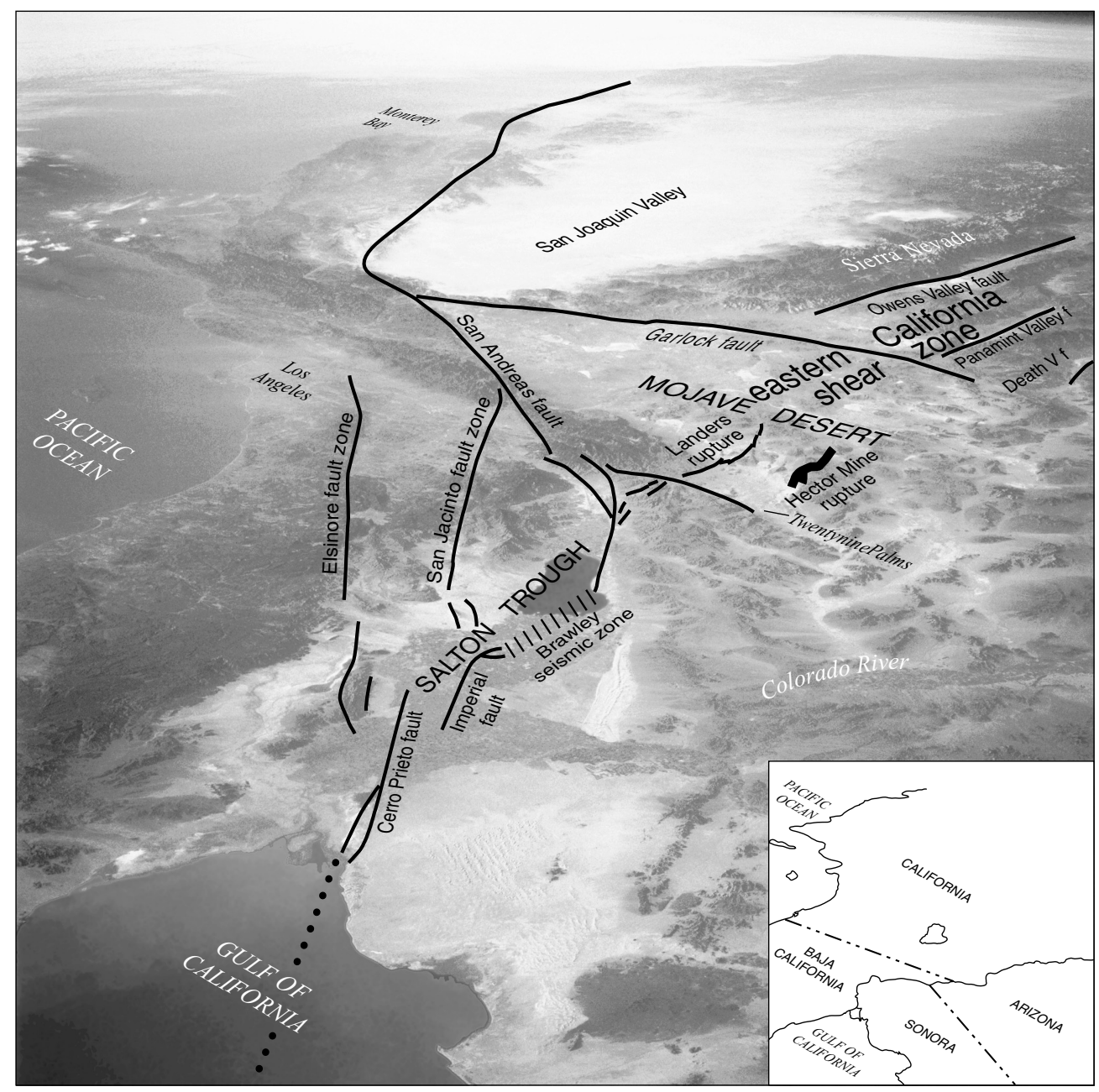

Figure 1. Oblique satellite view of northern Baja California, Mexico, westernmost Arizona, and all of southern California. Select cities, geographic features, and generalized traces of major faults drawn for reference. Hector Mine rupture (thick black line) and 1992 Landers rupture shown within eastern California shear zone. View to the northwest. Photograph from National Aeronautics and Space Administration (NASA) Johnson Space Center, Space Shuttle mission STS103, roll 701, frame 39, December 1999.

proportional to the slip and an average rupture velocity that is relatively slow compared to the Landers rupture velocity.

Wiemer et al. examine in great detail the Hector Mine aftershock sequence, particularly the spatial and temporal seismicity parameters, and compare it with the Landers sequence. Asymmetrical $b$-values and hazard patterns for both earthquakes lead to the hypothesis that mainshock rupture directivity and slip distribution influenced aftershock hazards. They compute probabilistic aftershock-hazard maps for the Hector Mine earthquake and suggest that greater hazards were in the northern part of aftershock zone. Stress field heterogeneity was unusually high near the Landers and Hector Mine hypocenters, particularly near patches of large slip.

Two articles estimate the amount of energy radiated from the Hector Mine earthquake. Although these two articles use different methods, regional and teleseismic estimates of radiated energy are in close agreement. Boatwright et al. use a revised spectral technique for estimating radiated energy. Their estimates of regional and teleseismic radiated energy are $3.4 \pm 0.7 \times 10^{22}$ dyne $\mathrm{cm}$ and $3.2 \times 10^{22}$ dyne $\mathrm{cm}$, respectively. They find little evidence of directivity in corrected velocity spectra. Venkataraman et al. also use regional data to estimate radiated energy. They remove path and station attenuation effects with an empirical Green's function deconvolution; the radiated energy is then computed using calculated source spectra. They determine a regional estimate of radiated energy of $3.0 \pm 0.9 \times 10^{15} \mathrm{~J}$. They also use two different techniques to estimate teleseismic energy of $1.8 \times 10^{15} \mathrm{~J}$ and $2.0 \times 10^{15} \mathrm{~J}$.

Kaverina et al. discuss inversion of broadband regional and local waveforms using GPS and InSAR measurements. They determine a peak slip of $5.5 \mathrm{~m}$ and a seismic moment $6.8 \times 10^{19} \mathrm{~N} \mathrm{~m}$. The majority of slip was on the western branch of the Lavic Lake fault, but overall rupture was bi- 


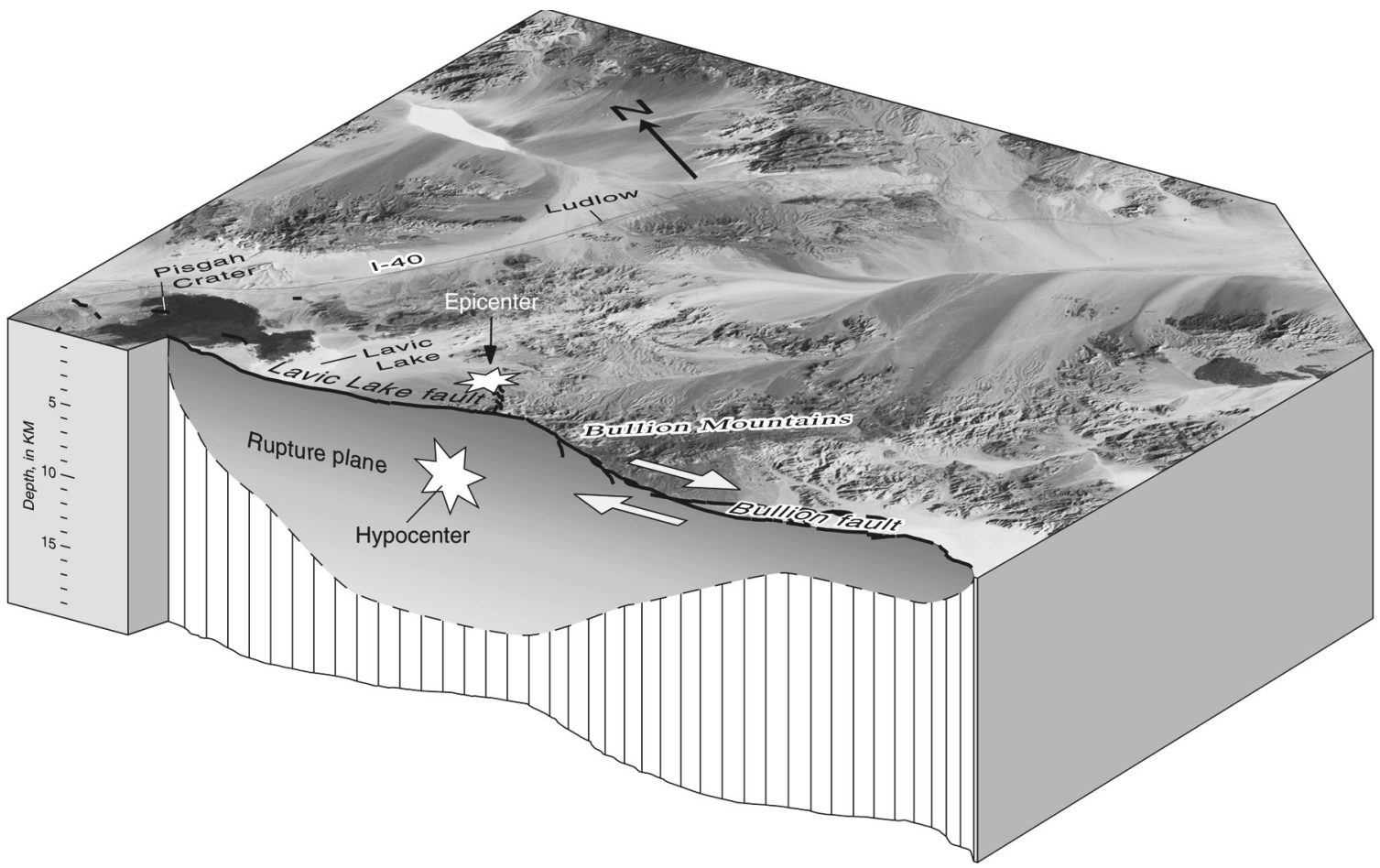

Figure 2. Schematic block diagram with vertical cut along 1999 Hector Mine rupture plane (Simons et al., 2002, this issue) and summarizing basic features and observations of the Hector Mine earthquake. View to the northeast. Features shown in this figure are generalized; for details see appropriate article in this issue. Magnitude, $M_{\mathrm{w}} 7.1$; Time, $9 \mathrm{~h} 46 \mathrm{~m}$ UTC, 16 October 1999; hypocentral depth, $5 \pm 4 \mathrm{~km}$ (Hauksson et al., 2002); seismic moment, $6.28 \times 10^{19} \mathrm{~N} \mathrm{~m}$ (Ji et al., 2002); average stress drop, 25 bars (Ji et al., 2002); length of surface rupture, $\sim 48 \mathrm{~km}$ (Treiman et al., 2002); maximum right lateral displacement, $5.5 \pm 0.5 \mathrm{~m}$; average along main rupture, $\sim 2.5 \mathrm{~m}$ (Treiman et al., 2002); faults involved: Lavic Lake, Bullion, East Bullion, West Bullion, Mesquite Lake, and unnamed faults (Treiman et al., 2002).

lateral. Average slip ranged from 1.6 to $2.7 \mathrm{~m}$ on the Lavic Lake and Bullion faults. They calculate a rupture velocity of $1.8 \mathrm{~km} / \mathrm{sec}$ with a delay of several seconds before the onset of significant slip.

Remotely triggered seismicity and surface fault slip are reported in the Salton Trough region, south-southeast of the Hector Mine rupture (Fig. 3). Hough and Kanamori examine earthquakes triggered beneath the Salton Sea and Imperial Valley, California. This study indicates that a $M 4.7$ earthquake triggered by the Hector Mine earthquake was followed by a local aftershock sequence. Source spectra are consistent with brittle shear failure and estimated stress drops are consistent with those observed elsewhere for tectonic earthquakes. They speculate that triggered earthquakes may tend to occur in geothermal and volcanic regions because shear failure can be triggered by relatively low stresses in extensional regimes. Glowacka et al. report measurements from a local deformation network in the Mexicali Valley, Baja California, Mexico, located about $260 \mathrm{~km}$ from the Hector Mine epicenter. The network includes crackmeters, tiltmeters, and a broadband seismograph, all recording continuously, along with other seismological instruments in the valley. Local earthquakes were recorded beginning $2 \mathrm{hr}$ after arrival of the Hector Mine seismic waves; local seismicity continued for about 2 weeks. Vertical and horizontal slip and tilt began on the Imperial fault simultaneously with passage of the Hector Mine seismic waves. Rymer, Boatwright, et al. examine surface slip that occurred along the southern San Andreas, Superstition Hills, and Imperial faults in association with the Hector Mine earthquake, making this at least the eighth time in the past 31 years that a regional earthquake has triggered slip along faults in the Salton Trough. Field evidence indicates a transient opening as the Hector Mine seismic waves passed the southern San Andreas fault. Comparison of nearby strong-motion records indicates several periods of relative opening - a similar process may have contributed to the field evidence of surface slip.

Li et al. study fault-zone-trapped waves across the Lavic Lake fault that show higher frequencies than those observed after the Landers rupture. Their data indicate a 75- to 100m-wide low-velocity rupture zone with a low $Q$ wave guide, in which $S$-wave velocity and $Q$ are reduced $40 \%-50 \%$ and $10 \%-60 \%$, respectively, from the surface to depths of $10 \mathrm{~km}$ (similar damage was observed along the Landers rupture). 


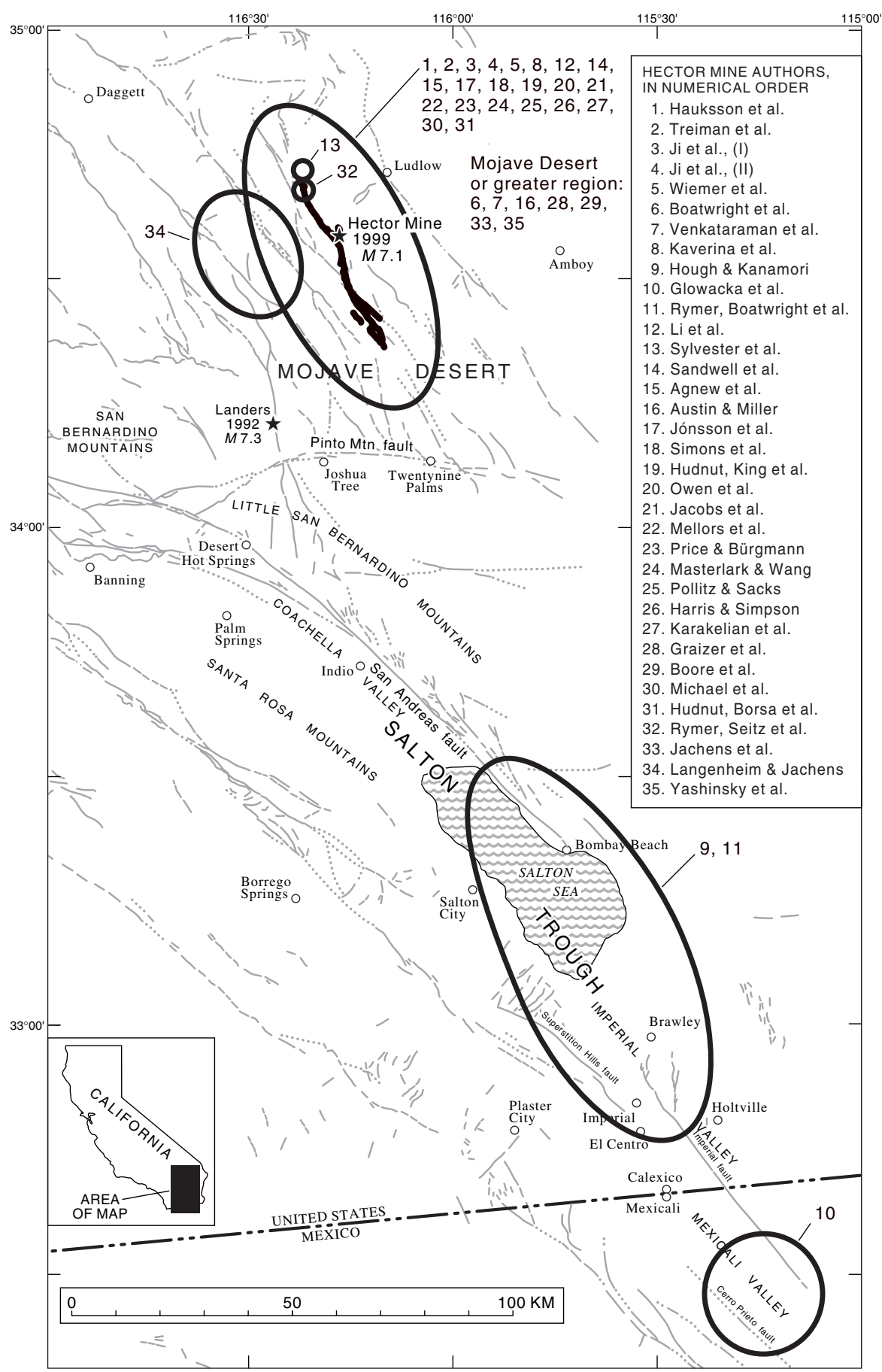

Figure 3. Index map of the 1999 Hector Mine earthquake and surface rupture. Also shown is the distribution of Quaternary active faults in the greater southern Mojave Desert and Salton Trough regions (modified from Jennings, 1994). Heavy line, Hector Mine surface faulting; 1992 Landers epicenter shown for reference. Also included is a generalized geographic distribution of topics covered in this special issue. Most reports cover the mainshock area, the associated surface rupture, geodetic measures of movement, and other effects of the earthquake. A large number of reports also cover the greater epicentral region, either as comparisons between the Hector Mine earthquake and the 1992 Landers shock or as geological, seismological, geophysical, or engineering studies over a wide region. A few reports cover restricted geographic areas away from the mainshock; included in this category are studies of remotely triggered seismicity and triggered slip, both of which occurred in the Salton Trough. 
They interpret this feature as a remnant of the process zone formed by inelastic deformation around the propagating crack tip during the rupture. They conclude that the process zone is half the length and width of that observed during the Landers event, which is consistent with scaling of process zone size to rupture zone.

Sylvester et al. report a 240-m-long zone of fractures and scarps near Pisgah Crater, north of the primary surface rupture. They infer that strong motion at Pisgah Crater was nearly three times that measured elsewhere by other investigators.

Sandwell et al. find good agreement in estimates of strike-slip offset from InSAR and geological measurements, except at the ends of the rupture. They calculate maximum dextral slip and dip slip of $6 \mathrm{~m}$ and $1 \mathrm{~m}$, respectively. They use both ascending and descending interferograms and show that at least two look directors are required for accurate estimates of surface slip even along a pure strike-slip fault.

Agnew et al. use GPS estimates of coseismic displacements that show strike-slip movement and evidence of significant uplift at one station. They were able to include preevent data because similar studies following the 1992 Landers earthquake provided a dense station coverage close to the 1999 rupture zone.

Austin and Miller recalculate the coseismic displacement fields of both Landers and Hector Mine earthquakes. Their calculations take advantage of well-established 1993 to 1999 velocities. GPS estimates of moment magnitude systematically underestimate the seismologically determined magnitude by $0.06-0.07$. They suggest evidence of kinematic loading of the Hector Mine rupture plane that substantiates predictions from new viscoelastic models.

Jónssen et al. use InSAR and campaign-mode GPS data to estimate the slip distribution. They model the rupture in nine segments; a constant-slip model indicates an average dip of $83^{\circ} \mathrm{NE}$ and slip up to $5.6 \mathrm{~m}$. A variable-slip model has both right-lateral and reverse faulting, with maximum horizontal displacement of $6 \mathrm{~m}$ and reverse faulting of 1.6 $\mathrm{m}$. In this latter model, maximum slip is located northwest of the epicenter. They estimate a geodetic moment of 5.93 $\times 10^{19} \mathrm{~N} \mathrm{~m}$, which is similar to seismological estimates and indicates there was no significant interseismic or postseismic deformation. Their model further indicates that the amount and extent of surface fault rupture may have been underestimated in the field.

Simons et al. use InSAR and GPS observations to investigate static deformation due to the Hector Mine earthquake. They use interferometric decorrelation, phase, and azimuthoffset measurements to indicate regions of surface and nearsurface slip. The interferograms indicate significant alongstrike variations in strain, consistent with ground-based observations. They also invert the InSAR and GPS data to derive subsurface fault geometry and distribution of slip. A layered model predicts more slip at depth than does a halfspace model. Maximum slip at depth is greater than $5 \mathrm{~m}$ at a depth of 3 to $6 \mathrm{~km}$, and the northern part of the Hector Mine rupture accommodating the maximum slip.

Hudnut, King, et al. describe rapid deployment of a new type of continuously operating GPS network. Analysis of these data combined with Southern California Integrated GPS Network (SCIGN) data indicates statistically significant time variation in the postseismic velocities at these sites. The postseismic velocity field is similar to that of the pre-Landers velocity field but is laterally shifted and locally twice the rate. They speculate that a portion of the crust east of the Landers rupture has now been entrained in flow along with the Pacific Plate as a result of the Landers and Hector Mine earthquake sequences.

Owen et al. surveyed a total of 55 sites for early postseismic survey-mode GPS measurements; stations were at distances from the Hector Mine rupture of a few meters to $100 \mathrm{~km}$. Velocity estimates for 32 sites are presented to provide reliable results. They calculate a simple afterslip model that shows observed velocities are consistent with deep afterslip located beneath the coseismic rupture area.

Jacobs et al. use InSAR data over the Hector Mine rupture area to reveal postseismic deformation of several centimeters. They evaluate interferograms representing four periods after the earthquake. The main deformation areas seen in displacement maps are as follows: a region of subsidence on the northern end of the rupture, an area of uplift located northeast of the primary fault bend, and a linear trough extending along the main rupture. They correlate these features with fault orientation and sense of slip. The temporal variations in near-fault postseismic deformation are similar to the relaxation times following the Landers earthquake. They derive an afterslip model that indicates much of the afterslip occurred at depths less than 3-4 km.

Mellors et al. use InSAR data to look for evidence of interseismic strain in the period between the 1992 Landers and 1999 Hector Mine earthquakes. They observe possible indicators of deformation associated with the 1992 Pisgah earthquake cluster, but high decorrelation prevents a conclusive determination. They see no evidence of precursory slip in the Hector Mine epicentral region to within 30 days before the event; they estimate a detection threshold equivalent to a magnitude 4.5 event would have been observable in the months prior to the Hector Mine earthquake.

The Hector Mine earthquake likely will never be thought of without comparison with the earlier, larger Landers earthquake. Four articles look at possible effects of the Landers earthquake that may have influenced the Hector Mine event. Because simple Coulomb static stress interactions do not predict an obvious cause-and-effect relationship between the Landers and Hector Mine earthquakes, Price and Bürgmann present a model of time-dependent fault friction to investigate the interaction between these events. They use detailed slip distributions inferred from GPS and InSAR data to compare stress changes on the Hector Mine rupture induced by the Landers event. The slip distributions are used 
to infer the shear stress drop on each earthquake rupture and the orientation of the remote background stress. They use a spring-and-slider model as a proxy for the rate-and-state frictional response of the Hector Mine rupture to the Landers event. They find that the decrease in normal stress would have triggered Hector Mine immediately, but the simultaneous decrease in shear stress caused a delay in peak shear loading from 0 to 40 years. Masterlark and Wang construct a 3D finite-element model to investigate transient stress coupling between the Landers and Hector Mine earthquakes, assuming a poroelastic upper crust and a viscoelastic lower crust. The model is constrained by GPS, InSAR, fluidpressure data from water wells, and the dislocation source of the Hector Mine earthquake. Pollitz and Sacks use a viscoelastic model calibrated by geodetic data to calculate the postseismic relaxation following the Landers event. The postseismic relaxation produced a transient increase in Coulomb failure stress of 0.7 bars on the Hector Mine rupture surface. The increase is largest over the broad surface that includes the nucleation point and site of peak slip. They argue that viscoelastic relaxation likely contributed to triggering of the Hector Mine earthquake, but their model relies on the assumption that the faults were critically stressed just prior to the Landers earthquake. Harris and Simpson test the stress shadow hypothesis for large earthquake interactions, using the Landers and Hector Mine earthquakes. They use four models of the Landers rupture and several possible hypocentral locations for the Hector Mine earthquake; most scenarios indicate a Landers-induced relaxation (stress shadow) on the Hector Mine hypocentral plane. However, taking into account the 1992 Pisgah earthquakes, the calculated Coulomb stress changes range from -0.3 to 0.3 $\mathrm{MPa}$. The Landers and Hector Mine pair of earthquakes does not provide a good test of the stress shadow hypothesis, mainly because of parametric and geometric uncertainties.

In the immediate aftermath of the Hector Mine earthquake, Karakelian et al. installed two electromagnetic (EM) monitoring systems to search for postmainshock activity and any precursory or coseismic EM signals associated with large aftershocks. They found no anomalous behavior clearly associated with seismic activity.

Two articles examine and analyze strong-motion data recorded from the Hector Mine earthquake. Graizer et al. show that the Hector Mine earthquake was recorded by more than 300 TriNet stations, which are administered cooperatively by the California Division of Mines and Geology/ California Strong Motion Instrument Program (CSMIP), Caltech, and the U.S. Geological Survey. The closest station to the epicenter was about $27 \mathrm{~km}$ to the north. This station, Hector, recorded a peak horizontal ground acceleration of $0.33 \mathrm{~g}$. The new digital instruments installed for TriNet recorded a large set of reliable peak ground motion attenuation relations at epicentral distances up to $275 \mathrm{~km}$. Boore et al. made an empirical study that illustrates the consequences of various baseline corrections to digital strong-motion data from the Hector Mine earthquake. This approach shows that simple processing produced displacement waveforms that are similar for stations separated by as much as $20 \mathrm{~km}$. A strong pulse on the transverse component was radiated from the Hector Mine earthquake and led to large response spectral amplitudes around $10 \mathrm{sec}$.

Given the paucity of strong-motion stations near the Hector Mine epicenter, Michael et al. estimate the minimum horizontal acceleration needed to dislodge rocks near the earthquake and its rupture. Their work implies that slightly lower than expected shaking occurred during the Hector Mine earthquake, given current empirical shaking-attenuation relationships. They did not observe an increased incidence of displaced rocks near the fault zone despite observations of fault-zone trapped waves generated by aftershocks; thus, these waves were not an important factor in controlling peak ground acceleration during the mainshock.

Hudnut, Borsa, et al. use a new technique of raster laser scan of the ground surface along the Hector Mine surface rupture to generate high-resolution topography. They show that by using such a technique they can then compare opposite sides of the ruptured fault to match offset geomorphic features (gullies and ridge spurs) to determine the amount of slip. They illustrate this approach in part of the main rupture area in the Bullion Mountains and compare their results with geologic field measurements.

Rymer, Seitz, et al. report on paleoseismic studies of the Lavic Lake fault at Lavic Lake playa, near the northern end of the Hector Mine rupture. Their studies indicate the timing of the penultimate earthquake occurred no earlier than about A.D. 260. Furthermore, they show there is abundant, subtle evidence for pre-1999 activity of the Lavic Lake fault in the playa area, even though the Lavic Lake fault was not mapped near the playa prior to the Hector Mine earthquake. Most notable indicators for long-term presence of the fault are pronounced, persistent vegetation lineaments and uplifted basalt exposures.

Two reports study potential-field data to analyze aspects of the tectonic setting for the Hector Mine earthquake. Jachens et al. estimate total long-term strike-slip offsets on faults in the Mojave Desert based on analysis of aeromagnetic data. Most long-term offsets are in the range of 3 to $5 \mathrm{~km}$, including the faults that ruptured during the Landers and Hector Mine earthquakes. The similarity in offset on a number of the Landers faults suggests (1) the multistrand nature of rupture for the Landers earthquake is a typical event or (2) this rupture path has acted as a coherent entity when viewed over some characteristic multiearthquake cycle. Basins in this part of the Mojave Desert are shallow, with the exception of Deadman Lake basin near the southern part of the Hector Mine rupture. Langenheim and Jachens study gravity and magnetic data that indicate a mafic crustal heterogeneity, most likely composed of Jurassic diorite exposed west of Emerson Lake, that lies between the Landers and Hector Mine epicenters. Aftershock seismicity and ruptures of both earthquakes occur outside the body; they argue that this crustal heterogeneity was an important influence on the 
rupture geometry of both earthquakes and may have played a role in transferring stress from the Landers rupture to the Hector Mine area.

In the continuing effort to understand the effects of earthquake shaking on man-made structures and to make such structures safer, Yashinsky et al. look at effects of the Hector Mine earthquake on bridges and highways, especially along Interstate 40. Little damage was done to these structures, even though they were within a distance of about 10 $\mathrm{km}$ of the Hector Mine surface rupture, well within the distance where bridges and highways commonly are affected. Most of the observed damage was the result of long-term problems for individual bridges - these problems apparently were exacerbated by the earthquake.

The Hector Mine earthquake fortunately caused no fatalities, but it provided the opportunity to use a wide variety of techniques and analytical methods to study a large strikeslip event in the remote, sparsely populated and sparsely vegetated Mojave Desert. The earthquake is the latest in a series of moderate to large earthquakes to occur within the ECSZ, further illustrating the tectonic importance of this zone of right-lateral shear. This earthquake and its larger cousin, the 1992 Landers earthquake, highlight the question of how strain is partitioned along this part of the plate boundary in southern California.

\section{Acknowledgments}

We thank Susan Hough and Rufus Catchings (both at the USGS) for constructive reviews and Michael Fehler, Neena Paul, and Carol Mark (Bulletin editorial staff) for their encouragement, cooperation, and patience in producing this special issue. We also thank the authors for their dedication to investigate aspects of the Hector Mine earthquake. Special thanks go to reviewers of all the articles presented in this special issue; their time, effort, and constructive comments improved the whole of the issue.

\section{References}

Dokka, R. K., and C. J. Travis (1990). Role of the eastern California shear zone in accommodating Pacific-North American plate motion, Geophys. Res. Lett. 17, 1323-1326.

Gan, W., J. L. Svarc, J. C. Savage, and W. H. Prescott (2000). Strain accumulation across the Eastern California Shear Zone at latitude $36^{\circ} 30^{\prime} \mathrm{N}$, J. Geophys. Res. 105, 16,229-16,236.
Hauksson, E., L. M. Jones, and K. Hutton (2002). The $1999 M_{\mathrm{w}}$ 7.1 Hector Mine, California earthquake sequence: complex conjugate strike-slip faulting, Bull. Seism. Soc. Am. 92, 1154-1170 (this issue).

Jennings, C. W. (Compiler) (1994). Fault activity map of California and adjacent areas, California Department of Conservation, Division of Mines and Geology, Geologic Data Map Series No. 6, scale $1: 750,000$.

Ji, C., D. J. Wald, and D. V. Helmberger (2002). Source description of the 1999 Hector Mine, California earthquake. Part II. Complexity of slip history, Bull. Seism. Soc. Am. 92, 1208-1226 (this issue).

Miller, M. M., D. J. Johnson, T. H. Dixon, and R. K. Dokka, (2001). Refined kinematics of the eastern California shear zone from GPS observations, 1993-1998, J. Geophys. Res. 106, 2245-2263.

Sauber, J., W. Thatcher, and S. C. Solomon (1986). Geodetic measurement of deformation in the central Mojave Desert, California, J. Geophys. Res. 91, 12,683-12,693.

Sauber, J., W. Thatcher, S. C. Solomon, and M. Lisowski (1994). Geodetic slip rate for the eastern California shear zone and the recurrence time of Mojave Desert earthquakes, Nature 367, 264-266.

Savage, J. C., M. Lisowski, and W. H. Prescott (1990). An apparent shear zone trending north-northwest across the Mojave desert in Owens Valley, eastern California, Geophys. Res. Lett. 17, 2113-2116.

Savage, J. C., W. Gan, and J. L. Svarc (2001). Strain accumulation and rotation in the Eastern California Shear Zone, J. Geophys. Res. 106, 21,995-22,007.

Scientists from the U.S. Geological Survey, Southern California Earthquake Center, and California Division of Mines and Geology (USGS, SCEC, and CDMG). (2000). Preliminary report on the 16 October $1999 M$ 7.1 Hector Mine, California, earthquake, Seism. Res. Lett. 71, 11-23.

Simons, M., Y. Fialko, and L. Rivera (2002). Coseismic deformation from the $1999 \mathrm{M}_{\mathrm{w}}$ 7.1 Hector Mine, California earthquake as inferred from InSAR and GPS observations, Bull. Seism. Soc. Am. 92, 1390-1402 (this issue).

Treiman, J. A., K. J. Kendrick, W. A. Bryant, T. K. Rockwell, and S. F. McGill (2002). Primary surface rupture associated with the $M_{\mathrm{w}} 7.1$ 16 October 1999 Hector Mine earthquake, San Bernardino County, California, Bull. Seism. Soc. Am. 92, 1171-1191 (this issue).

U.S. Geological Survey

345 Middlefield Road, MS 977

Menlo Park, California 94025

(V.E.L., M.J.R.)

Seismological Laboratory

California Institute of Technology

Pasadena, California 91125

(E.H.)

Manuscript received 16 March 2002. 